\title{
Papers
}

\section{Surgical stabilisation of the spine compared with a programme of intensive rehabilitation for the management of patients with chronic low back pain: cost utility analysis based on a randomised controlled trial}

Oliver Rivero-Arias, Helen Campbell, Alastair Gray, Jeremy Fairbank, Helen Frost, James Wilson-MacDonald for the Spine Stabilisation Trial Group

\begin{abstract}
Objective To determine whether, from a health provider and patient perspective, surgical stabilisation of the spine is cost effective when compared with an intensive programme of rehabilitation in patients with chronic low back pain. Design Economic evaluation alongside a pragmatic randomised controlled trial.

Setting Secondary care.

Participants 349 patients randomised to surgery $(n=176)$ or to an intensive rehabilitation programme $(\mathrm{n}=173)$ from 15 centres across the United Kingdom between June 1996 and February 2002.

Main outcome measures Costs related to back pain and incurred by the NHS and patients up to 24 months after randomisation. Return to paid employment and total hours worked. Patient utility as estimated by using the EuroQol EQ-5D questionnaire at several time points and used to calculate quality adjusted life years (QALYs). Cost effectiveness was expressed as an incremental cost per QALY.

Results At two years, 38 patients randomised to rehabilitation had received rehabilitation and surgery whereas just seven surgery patients had received both treatments. The mean total cost per patient was estimated to be $£ 7830$ (SD £5202) in the surgery group and $£ 4526$ (SD £4155) in the intensive rehabilitation arm, a significant difference of $£ 3304$ (95\% confidence interval £2317 to £4291). Mean QALYs over the trial period were 1.004 (SD 0.405) in the surgery group and 0.936 (SD 0.431) in the intensive rehabilitation group, giving a non-significant difference of $0.068(-0.020$ to 0.156$)$. The incremental cost effectiveness ratio was estimated to be $£ 48588$ per QALY gained ( $-£ 279883$ to $£ 372406$ ).

Conclusion Two year follow-up data show that surgical stabilisation of the spine may not be a cost effective use of scarce healthcare resources. However, sensitivity analyses show that this could change--for example, if the proportion of rehabilitation patients requiring subsequent surgery continues to increase.
\end{abstract}

\section{Introduction}

Chronic low back pain, defined as pain lasting for more than three months, is common and places a major economic burden on individuals, the healthcare system, and society as a whole.
Direct costs associated with the disability were estimated to be around $£ 1.6$ bn in the United Kingdom in 1998, ${ }^{1}$ and the condition is estimated to be responsible for close to 120 million UK work days lost per year. ${ }^{2}$

The optimal treatment strategy for patients with chronic low back pain in whom conservative therapy has failed remains uncertain. For three trials, the results of randomised comparisons between surgical and conservative management techniques have been published. ${ }^{3-5}$ Evidence from these trials shows that surgery may have some clinical benefit, but it is not clear whether intensive rehabilitation in conjunction with cognitive educational programmes can generate similar benefits for patients. Results from the first UK based trial, the spine stabilisation trial, show a significant difference in the Oswestry disability index at two years in patients randomised to spinal fusion surgery compared with intensive rehabilitation, which is arguably of clinical importance. ${ }^{6}$ This statistical difference between treatment groups in only one of the two primary outcome measures was marginal and only just reached the predefined minimal clinical difference. The potential risk and additional cost of surgery also need to be considered. No clear evidence emerged that primary fusion was any more beneficial than intensive rehabilitation. We report an economic evaluation conducted prospectively alongside the UK spine stabilisation trial. We employ a cost utility framework to determine whether any net health gain from using surgery would be sufficient to justify a likely increase in the costs of treatment. The chosen form of analysis will facilitate comparisons between the cost effectiveness of surgery and that of other healthcare interventions competing for healthcare resources.

\section{Methods}

Full details of the randomised controlled trial are published in parallel with this paper. ${ }^{6}$ Briefly, the trial was powered to detect a four point difference on the Oswestry disability index (a questionnaire designed to assess limitations of various activities of daily living ${ }^{78}$ ) between surgery and intensive rehabilitation at 24 months. We recruited 349 patients who met trial eligibility criteria from 15 centres around the UK between June 1996 and

Additional details of the costing method, the participating units, and the members of the MRC steering committee are on bmj.com 
February 2002. Of these patients, 176 were randomised to spinal fusion surgery and 173 to intensive rehabilitation.

For surgery patients, the local operating surgeon decided the type of spinal stabilisation used. Rehabilitation patients attended a paced exercise and education programme based on principles of cognitive behaviour therapy totalling about 75 hoursl. We followed patients and collected back pain related NHS data and data on use of resources by patients to 24 months after randomisation. Patients who considered that their allocated treatment for chronic low back pain had failed could have further treatment including surgery. At baseline, six, 12, and 24 months, patients completed the EuroQol EQ-5D questionnaire, a generic health outcome instrument used to estimate utility scores ${ }^{9}$ and quality adjusted life years (QALYs).

\section{Resource use}

Patient specific data on the use of NHS resources included initial treatments, other back pain related hospital inpatient and outpatient visits, primary care contacts, and prescribed items of medication. We also collected data on over the counter medications purchased and visits made to private practitioners. The number of centres participating in the trial and constraints on resources precluded the collection of centre specific unit costs. Unless otherwise indicated, we used national average unit costs. All costs calculated are expressed in 2002-3 pounds sterling, inflated to this base year where appropriate. ${ }^{10}$

\section{Spinal fusion surgery}

A "micro" approach to the costing of surgery used patient specific data itemised by use of resources. We costed duration spent by each patient in the operating theatre to allow for the time of staff involved and use of the theatre. ${ }^{10}{ }^{11}$ We used unit costs obtained from the lead investigating centre to value types and numbers of surgical implants and intraoperative spinal $\mathrm{x}$ rays.

We calculated costs for anaesthetic agents and blood products administered during each patient's surgery. ${ }^{12}$ We assumed that the costs of any surgical complications were reflected in the time spent by the patient in theatre. Finally, we costed each patient's surgery related inpatient stay in hospital. ${ }^{13}$

\section{Intensive rehabilitation}

For each patient, we collected information on the number of half day rehabilitation sessions attended and applied staff costs per session. ${ }^{10}$ Patients had one hydrotherapy session per day, valued by using a unit cost from the lead investigating centre. We costed exercise equipment and use of the hospital gym and a meeting room, by adding $15 \%$ (the overhead rate employed by the lead investigating centre) to staff, hydrotherapy, and equipment costs. Finally, we costed overnight accommodation at either a private bed and breakfast (paid for by the NHS) or on a hospital ward. ${ }^{14}$

\section{Other back pain related NHS contacts}

Patients reported attendances at hospital outpatient clinics for spinal surgery, physiotherapy, and other back pain related care at six, 12, and 24 months, which we then costed. ${ }^{10} 131516$ We used the mean cost of the initial fusion procedures (calculated as described above) to cost hospital admissions for unplanned spinal fusion surgeries. Admissions for investigations included the cost of the evaluative procedure (provided by the lead investigating centre) plus overnight hotel costs on a general medical ward. ${ }^{14}$ We costed visits to and home visits from general practitioners and practice nurses. ${ }^{10}$ We used the average cost of a rehabilitation programme (calculated as described above) to cost any additional intensive rehabilitation.

\section{Patients' costs}

Patients reported contacts with private complementary practitioners, for which we obtained costs from relevant national organisations. Patients also documented items of medication prescribed, and the cost of over the counter medication purchased for back pain (see bmj.com for more details of costing methods).

\section{Paid employment}

Patients reported their employment status, occupation, and hours worked at baseline, six, 12, and 24 months. We calculated and costed total hours worked by each patient. ${ }^{17}$

Health related quality of life and quality adjusted life years We used the EuroQol EQ-5D social tariff, estimated from a representative sample of the UK population, to convert patients' responses to the EuroQol EQ-5D questionnaire at baseline, six, 12, and 24 months into single utility levels. ${ }^{18}$ We then constructed patient specific utility profiles, assuming a straight line relation between each of the patient's utility levels. We calculated the number of QALYs experienced by each patient from baseline to 24 months as the area beneath this profile.

\section{Discounting}

We discounted costs and effects at an annual rate of $3.5 \%{ }^{19}$

\section{Statistical analysis}

A small amount of trial data (12\% of follow-up resource use items, $10 \%$ of utility scores, and $14 \%$ of work status data) were missing between baseline and 24 months. We used multiple imputation, ${ }^{20}$ which replaces each missing value with a set of $\mathrm{m}$ plausible values, to generate three replacement values $(m=3)$ for each of the missing cells in these datasets, using multiple linear regression models containing the covariates intervention group, age, and sex. Arithmetic means presented for resource use, costs, and QALYs in each trial arm are an average of the means from the three datasets created. Associated standard deviations include a variance correction factor to account for variability as a result of the imputation process.

Arithmetic means and 95\% confidence intervals are presented when making cost and QALY comparisons between the two arms of the trial. Skewness in cost data was modest, and we therefore report conventional parametric confidence intervals.

We carried out incremental analysis, with the mean cost difference between surgery and rehabilitation divided by the mean QALY difference to give the incremental cost effectiveness ratio (ICER). The non-parametric percentile method $^{21}$ for calculating the confidence interval around this ratio used 1000 bootstrap estimates of the mean cost and QALY differences. We used the cost effectiveness acceptability curve to show the probability that surgery is cost effective at two years for different values of the NHS's willingness to pay for an additional QALY. ${ }^{22}$

\section{Results}

Baseline patient characteristics are summarised in table 1 and reported in detail in the companion paper. ${ }^{6}$

\section{Resource use and costs: initial interventions}

Surgery-Spinal stabilisation was carried out for 139/176 $(79 \%)$ patients randomised to surgery. Procedures were divided into three different groups: posterolateral fusion $(n=57), 360^{\circ}$ fusion $(\mathrm{n}=57)$, and Graf stabilisation $(\mathrm{n}=25)$. Table 2 presents data on use of surgical resources and cost, averaged across all 139 patients who had surgery. The mean total cost of a spinal 
Table 1 Patients' demographics at baseline. Values are numbers (percentages) of patients unless otherwise indicated

\begin{tabular}{lcc} 
Characteristic & Surgery group ( $\mathbf{n}=\mathbf{1 7 6})$ & Rehabilitation group ( $\mathbf{n}=\mathbf{1 7 3})$ \\
\hline Male & $79(44.9)$ & $93(53.8)$ \\
\hline Female & $97(55.1)$ & $80(46.2)$ \\
\hline Age: & $24(13.6)$ & $20(11.6)$ \\
\hline$<30$ years & $63(35.8)$ & $67(38.7)$ \\
\hline $30-39$ years & $56(31.8)$ & $66(38.1)$ \\
\hline $40-49$ years & $33(18.8)$ & $20(11.6)$ \\
\hline$\geq 50$ years & $8(1-35)$ & $8(1-35)$ \\
\hline $\begin{array}{l}\text { Median (range) duration of } \\
\text { back pain in years }\end{array}$ & & \\
\hline
\end{tabular}

operation was estimated at $£ 7610$ (SD £2643). Zero surgery costs were assigned to the 37 patients who did not have spinal fusion and an average treatment cost of $£ 6011$ (SD £3896) calculated across all surgery patients.

Intensive rehabilitation -151/173 (87\%) of the patients randomised to intensive rehabilitation attended some proportion of their programme. Table 2 shows a breakdown of the mean total cost of intensive rehabilitation among the 151 patients who attended rehabilitation. The total cost was estimated to be $£ 1615$ (SD £644). Including zero rehabilitation programme costs for the 22 patients who did not attend, averaging across all 173 patients generated a cost estimate of $£ 1410$ (SD £808).

Intensive rehabilitation was substantially less costly than surgery (cost difference $£ 4601,95 \%$ confidence interval $£ 4013$ to $£ 5189$, $\mathrm{P}<0.001)$.

\section{Other back pain related NHS costs}

Forty eight patients randomised to rehabilitation underwent surgical stabilisation of the spine -10 instead of rehabilitation, 38 in addition to rehabilitation. Table 3 shows that these unplanned surgery costs averaged $£ 2128$ per patient across the rehabilitation group. This was greater than the corresponding cost of $£ 451$ in the surgery group, which was primarily attributable to 11 patients who required spinal re-operations.

Fourteen surgery patients underwent unplanned intensive rehabilitation (seven instead of surgery, seven as well as surgery). These costs amounted to $£ 162$ per patient. The overall mean cost per patient of follow-up back pain related NHS contacts was $£ 1302$ lower in the surgery group $(95 \%$ confidence interval $-£ 1999$ to $-£ 605, \mathrm{P}<0.001)$.

\section{Patient costs}

Table 3 shows that patient costs related to back pain were similar in both arms.

\section{Overall costs}

Table 4 shows that at two years, spinal fusion costs $£ 7830$ (SD $£ 5202$ ), and intensive rehabilitation $£ 4526$ (SD £4155). The cost difference of $£ 3304$ favoured intensive rehabilitation ( $£ 2317$ to $£ 4291, \mathrm{P}<0.001)$.

\section{Return to work}

At baseline, 88/176 (50\%) of the surgery group and 79/173 $(46 \%)$ of the rehabilitation group were not in paid employment. By 24 months, 18 of these 88 in the surgery group (20\%) and 19 of the 79 in the rehabilitation group (24\%) had started some form of employment, a non-significant difference of $4 \%$ ( $-8 \%$ to $12 \%, \mathrm{P}=0.71$ ). The mean number of days to obtaining paid employment was 326 (SD 167) days and 323 (SD 278) days, respectively.

The mean total number of hours worked from baseline to 24 months in the surgery group was 1678 (SD 1847) hours and in

Table 2 Breakdown of resource use and costs associated with initial treatments (in 2002-3 pounds sterling)

\begin{tabular}{|c|c|c|c|c|}
\hline \multirow[b]{2}{*}{ Resource use item } & \multicolumn{2}{|c|}{ Mean (SD) resource use per patient* } & \multicolumn{2}{|c|}{ Mean (SD) cost per patient* } \\
\hline & Surgery $(n=139)$ & Rehabilitation ( $n=151)$ & Surgery $(n=139)$ & Rehabilitation $(n=151)$ \\
\hline \multicolumn{5}{|l|}{ Surgical stabilisation } \\
\hline Duration in theatre in minutes & $182(76)$ & $\mathrm{N} / \mathrm{A}$ & & \\
\hline \multicolumn{5}{|l|}{ Costs related to theatre duration: } \\
\hline Cost of theatre per se & & & $£ 204(£ 85)$ & N/A \\
\hline Cost of theatre personnel & & & $£ 2635$ (£1409) & $\mathrm{N} / \mathrm{A}$ \\
\hline Cost of anaesthetics $\dagger$ & & & $£ 24.07$ (£29.55) & $\mathrm{N} / \mathrm{A}$ \\
\hline Radiographył & $0.69(1.06)$ & $\mathrm{N} / \mathrm{A}$ & $£ 18.39$ (£24.48) & $\mathrm{N} / \mathrm{A}$ \\
\hline Surgical implants used & $96 \% \S$ & $\mathrm{N} / \mathrm{A}$ & $£ 1703$ (£1589) & $\mathrm{N} / \mathrm{A}$ \\
\hline Blood products used & $18 \% \S$ & $\mathrm{N} / \mathrm{A}$ & $£ 77.79$ (£241) & $\mathrm{N} / \mathrm{A}$ \\
\hline $\begin{array}{l}\text { Surgery related inpatient hospital stay in } \\
\text { days }\end{array}$ & $7.70(3.13)$ & $\mathrm{N} / \mathrm{A}$ & $£ 2933(£ 1192)$ & $\mathrm{N} / \mathrm{A}$ \\
\hline $\begin{array}{l}\text { Mean total cost of a surgical stabilisation } \\
\text { operationף }\end{array}$ & & & $£ 7610$ (£2643) & $\mathrm{N} / \mathrm{A}$ \\
\hline \multicolumn{5}{|l|}{ Intensive rehabilitation } \\
\hline $\begin{array}{l}\text { Number of half day rehabilitation sessions } \\
\text { attended }\end{array}$ & $\mathrm{N} / \mathrm{A}$ & $26.32(6.94)$ & & \\
\hline \multicolumn{5}{|l|}{ Costs related to session attendance: } \\
\hline Cost of programme personnel & & & $\mathrm{N} / \mathrm{A}$ & $£ 513.79(£ 135.51)$ \\
\hline Cost of hospital gym or exercise rooms & & & $\mathrm{N} / \mathrm{A}$ & $£ 223.70(£ 59)$ \\
\hline Cost of hydrotherapy sessions & & & $\mathrm{N} / \mathrm{A}$ & $£ 526.36(£ 138.82)$ \\
\hline Accommodation required & N/A & $36.5 \% \S$ & $\mathrm{N} / \mathrm{A}$ & $£ 350.81$ (£506.99) \\
\hline $\begin{array}{l}\text { Mean total cost of a course of intensive } \\
\text { rehabilitation** }\end{array}$ & & & $\mathrm{N} / \mathrm{A}$ & $£ 1615(£ 644)$ \\
\hline Mean total cost of interventions & & & $£ 6011$ (£3896)†† & $£ 1410(£ 808) \dagger †$ \\
\hline
\end{tabular}

$\mathrm{N} / \mathrm{A}=$ Not applicable.

${ }^{*}$ Calculated for 139/176 surgery patients and 151/173 rehabilitation patients receiving allocated therapy.

†Includes cost of administering and monitoring anaesthetics.

†Includes cost of radiography plus a 30 minute allocation of radiographer time.

§Proportion of patients consuming resource.

IIncludes low cost items not shown in the table-that is, use of image intensifier and post-operative pain control costing £0.20 and £14.82 per patient, respectively.

$* *$ Includes low cost item not shown in table-that is, exercise equipment (chair and mat) at £0.74 per patient.

††Calculated across all 176 surgery patients and all 173 rehabilitation patients. 


\begin{tabular}{|c|c|c|c|c|c|}
\hline \multirow[b]{2}{*}{ Resource use item } & \multicolumn{2}{|c|}{ Mean (SD) No per patient } & \multicolumn{2}{|c|}{ Mean (SD) cost per patient } & \multirow{2}{*}{$\begin{array}{l}\text { Mean cost difference (95\% } \\
\text { parametric } \mathrm{Cl})\end{array}$} \\
\hline & Surgery $(n=176)$ & Rehabilitation ( $\mathrm{n}=173)$ & Surgery $(n=176)$ & Rehabilitation ( $n=173)$ & \\
\hline \multicolumn{6}{|c|}{ Other back pain related NHS contacts } \\
\hline $\begin{array}{l}\text { Surgery related follow-up } \\
\text { outpatient clinics }\end{array}$ & $2.87(2.41)$ & $1.21(1.77)$ & $£ 190$ (£159) & $£ 82(£ 119)$ & $£ 108(£ 78 \text { to } £ 137)^{*}$ \\
\hline Physiotherapy outpatient clinics & $3.88(7.09)$ & $3.91(7.60)$ & $£ 286(£ 523)$ & $£ 301(£ 584)$ & $-£ 15$ (-£131 to £101) \\
\hline $\begin{array}{l}\text { Other back pain related outpatient } \\
\text { clinics }\end{array}$ & $2.06(4.33)$ & $2.51(6.41)$ & $£ 124$ (£241) & $£ 121$ (£224) & $£ 3(-£ 46$ to $£ 52)$ \\
\hline $\begin{array}{l}\text { Unplanned hospital admissions for } \\
\text { spinal surgery }\end{array}$ & $0.07(0.27)$ & $0.31(0.50)$ & $£ 451(£ 1881)$ & $£ 2128$ (£3522) & $-£ 1677(-£ 2271 \text { to }-£ 1083)^{\star}$ \\
\hline $\begin{array}{l}\text { Other back pain related hospital } \\
\text { admissions }\end{array}$ & $0.18(0.49)$ & $0.07(0.25)$ & $£ 130(£ 910)$ & $£ 73(£ 555)$ & $£ 57 \quad(-£ 101$ to $£ 215)$ \\
\hline General practitioner consultations & $7.38(9.23)$ & $6.81(8.49)$ & $£ 198$ (£232) & $£ 185(£ 212)$ & $£ 13 \quad(-£ 33$ to $£ 60)$ \\
\hline Practice nurse consultations & $0.86(2.09)$ & $0.62(1.84)$ & $£ 15(£ 35)$ & $£ 11(£ 31)$ & $£ 4(-£ 3$ to $£ 11)$ \\
\hline General practitioner home visits & $0.69(1.81)$ & $0.31(1.03)$ & $£ 44(£ 113)$ & $£ 19(£ 62)$ & $£ 24$ (£5 to $£ 43) \dagger$ \\
\hline Practice nurse home visits & $0.61(2.07)$ & $0.24(1.15)$ & $£ 12(£ 41)$ & $£ 4(£ 18)$ & $£ 8$ (£2 to £15)† \\
\hline $\begin{array}{l}\text { Patients attending unplanned } \\
\text { intensive rehabilitation }\end{array}$ & 14 & 0 & $£ 162(£ 453)$ & $£ 0$ & $£ 162(£ 94$ to £229)* \\
\hline Prescriptions received & $14.23(27.05)$ & $13.43(20.26)$ & $£ 95(£ 200)$ & $£ 84(£ 141)$ & $£ 11(-£ 25$ to $£ 46)$ \\
\hline $\begin{array}{l}\text { Total other back pain related NHS } \\
\text { contact costs }\end{array}$ & & & $£ 1707$ (£2451) & $£ 3009$ (£4001) & $-£ 1302(-£ 1999 \text { to }-£ 605)^{*}$ \\
\hline \multicolumn{6}{|l|}{ Back pain related costs to patients } \\
\hline $\begin{array}{l}\text { Visits to complementary } \\
\text { practitioners }\end{array}$ & $4.00(13.19)$ & $2.77(11.70)$ & $£ 89(£ 325)$ & $£ 92(£ 501)$ & $-£ 3 \quad(-£ 92$ to $£ 86)$ \\
\hline $\begin{array}{l}\text { Home visits from complementary } \\
\text { practitioners }\end{array}$ & $0.19(2.26)$ & $0.03(0.17)$ & $£ 6(£ 71)$ & $£ 1(£ 5)$ & $£ 5(-£ 6$ to $£ 15)$ \\
\hline $\begin{array}{l}\text { Items of over the counter } \\
\text { medication purchased }\end{array}$ & $\mathrm{N} / \mathrm{A}$ & $\mathrm{N} / \mathrm{A}$ & $£ 17(£ 34)$ & $£ 14(£ 36)$ & $£ 3(-£ 4$ to £11) \\
\hline $\begin{array}{l}\text { Total back pain related patient } \\
\text { costs }\end{array}$ & & & $£ 112(£ 350)$ & $£ 107$ (£502) & $£ 5(-£ 86$ to $£ 96)$ \\
\hline $\begin{array}{l}\text { Total back pain related follow-up } \\
\text { costs }\end{array}$ & & & $£ 1819$ (£2511) & $£ 3116(£ 4120)$ & $-£ 1297(-£ 2014 \text { to }-£ 580)^{*}$ \\
\hline
\end{tabular}

$\mathrm{N} / \mathrm{A}=$ Not available

${ }^{*} \mathrm{P} \leq 0.001$.

$\dagger P<0.05$.

the rehabilitation group 1707 (SD 1870) hours (difference - 29, $95 \%$ confidence interval -419 hours to 361 hours, $\mathrm{P}=0.89$ ). Corresponding gross earnings were $£ 19648$ (SD £22 256) and $£ 20034$ (SD £22 564), respectively-a non-significant difference of $-£ 386$ ( $-£ 5088$ to $£ 4317, \mathrm{P}=0.87$ ).

\section{Utility}

Figure 1 shows utility levels at baseline, six, 12, and 24 months. We found no significant differences in utility at any of the follow-up points. A notable difference in utility existed at baseline (0.35 for surgery, 0.41 for rehabilitation). Adjusting for such a difference (using a regression based approach with trial arm and baseline score as explanatory variables) and recalculating the area under utility frontiers specific to patients produced a mean QALY difference in favour of surgery of $0.068(-0.02$ to $0.156, \mathrm{P}=0.13$; mean 1.004 (SD 0.405$)$ for surgery and 0.936 (SD $0.431)$ for rehabilitation).

\section{Cost utility}

The incremental cost per QALY of using a policy of immediate surgery was estimated to be $£ 48588$ ( $-£ 279883$ to $£ 372406$ ).
Figure 2 shows the cost effectiveness acceptability curve. Reading off from the curve shows that if decision makers are willing to pay $£ 30000$ for a QALY (the value above which the National Institute for Clinical Excellence is less likely to accept a technology as cost effective ${ }^{23}$ ), at two years, the chance that surgery will be cost effective is less than $20 \%$.

\section{Sensitivity analysis}

Although uncertainty surrounds several trial variables, alternative assumptions for some would not affect the baseline conclusion. For example, replacing unit costs provided by the lead investigating centre with national averages had they been available would make little difference. Similarly, alternative discount rates will have little effect over a two year time horizon.

We used sensitivity analysis to examine uncertainty surrounding the use of different surgical techniques for spinal stabilisation. Assuming any patient in the trial receiving surgery underwent posterolateral fusion, the least costly technique at $£ 6170$ ( $£ 5638$ to $£ 6803$ ), reduced the total cost in the surgery group to $£ 6655$ and in the rehabilitation group to $£ 4252$. The

Table 4 Summary of initial treatment and 24 month follow-up costs (2002-03 pounds sterling)

\begin{tabular}{|c|c|c|c|}
\hline & Surgery group $(\mathrm{n}=176)$ & Rehabilitation group $(\mathrm{n}=173)$ & \\
\hline Cost category & Mean (SD) cost per patient & Mean (SD) cost per patient & Mean cost difference $(95 \%$ parametric $\mathrm{CI}$ \\
\hline Initial treatment cost & $£ 6011$ (£3896) & $£ 1410(£ 808)$ & $£ 4601(£ 4013 \text { to } £ 5189)^{*}$ \\
\hline $\begin{array}{l}\text { Other back pain related NHS contacts at } 24 \\
\text { months }\end{array}$ & $£ 1707$ (£2451) & $£ 3009$ (£4001) & $-£ 1302(-£ 1999 \text { to }-£ 605)^{*}$ \\
\hline Total NHS cost & $£ 7718(£ 5138)$ & $£ 4419(£ 4026)$ & $£ 3299$ (£2322 to £4267) \\
\hline Back pain related patient costs at 24 months & $£ 112(£ 350)$ & $£ 107(£ 502)$ & $£ 5(-£ 86$ to $£ 96)$ \\
\hline Total cost of care & $£ 7830$ (£5202) & $£ 4526(£ 4155)$ & $£ 3304$ (£2317 to £4291)* \\
\hline
\end{tabular}

${ }^{*} \mathrm{P}<0.001$. 


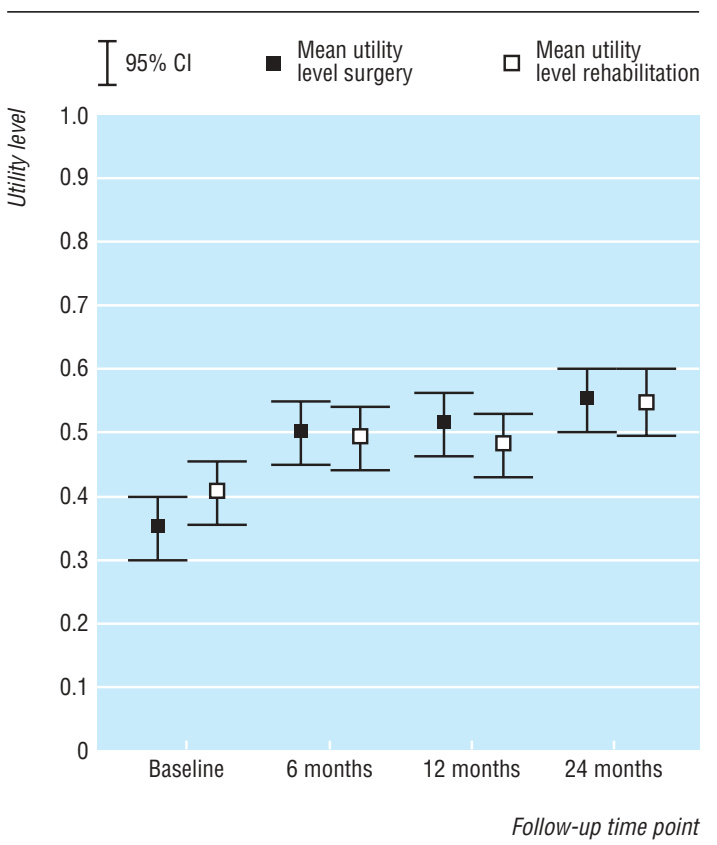

Fig 1 Mean utility levels (with 95\% confidence intervals) generated by applying the EuroQol EQ-5D social tariff to patients' self reported health state descriptions

incremental cost per QALY fell to $£ 35338$ ( $£ 188876$ to $£ 410404$ ). Alternatively had all patients undergone $360^{\circ}$ fusion, the most costly technique at $£ 9279$ ( $£ 8632$ to $£ 9917$ ), then the mean cost difference would have increased to $£ 4132$ ( $£ 3065$ to $£ 5199)$ and the incremental cost per QALY to $£ 60765$ ( $-£ 420210$ to $£ 617081$ ).

If the difference in utility observed at 24 months $(0.566$ for surgery and 0.532 for rehabilitation after adjustments for baseline) was maintained for a further two years, the incremental cost per QALY at four years would fall to $£ 25398$ (£13 121 to $£ 75$ 916).

We also examined the impact of patients receiving other treatments subsequent to their allocated therapy. At two years, 45 patients (38 in the rehabilitation group and seven in the surgery group) had received both treatments under comparison. Holding all else constant and assuming patients in each arm would continue to receive both treatments in years three, four, and five at the rates observed in years one and two, the cost difference is reduced to $£ 1144$ ( $-£ 312$ to $£ 2600)$ and the cost per QALY to $£ 16824$ ( $-£ 156358$ to $£ 138911$ ). If the trend contin-

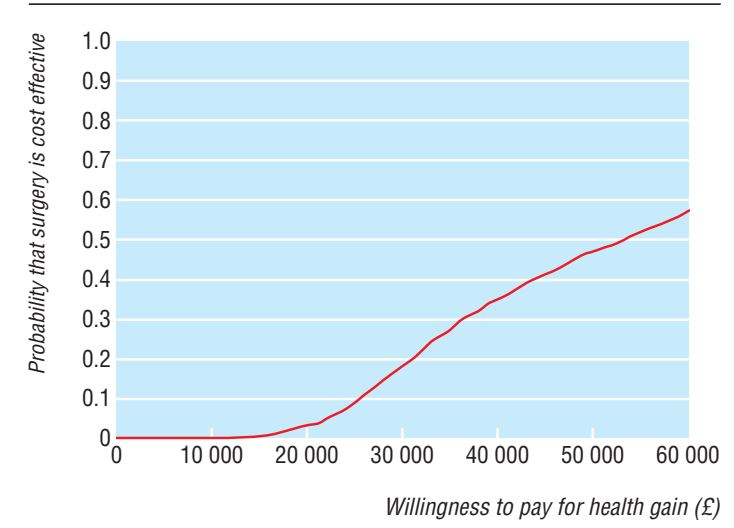

Fig 2 Cost effectiveness acceptability curve showing the probability that surgery is cost effective for different ceilings of willingness to pay ued but at half the rate observed in years one and two, the excess cost of the surgery arm at five years would fall to $£ 2165$ ( $£ 904$ to $£ 3425$ ) and the cost per QALY to $£ 31838$ ( $-£ 407056$ to $£ 283783)$.

\section{Discussion}

A policy in which patients receive spinal fusion surgery as first line therapy for their chronic low back pain seems not to be a cost effective use of healthcare resources at two year follow-up

\section{Strengths of the study}

The main strength of this study lies in the pragmatic approach adopted by the randomised controlled trial. Patients were not denied alternative healthcare interventions for chronic pain of the low back, and consequently the treatment patterns observed are likely to reflect those prevailing in routine practice.

At 24 months, the numbers of patients receiving both trial interventions differed significantly between the two arms. It is possible that this difference will increase beyond the two year follow-up point, and sensitivity analyses have shown that this could substantially affect the cost effectiveness of surgery.

Our study found no significant differences in work status measures. Employment data were available from two of the three previously published randomised trials comparing surgical and conservative intervention for chronic pain of the low back. ${ }^{35}$ The number of patients returning to work differed between arms (in favour of surgery) in one of these trials, but the same trial found no significant differences in the mean number of sick days per patient and resulting productivity costs at 24 months. ${ }^{54}$

This paper presents a cost utility analysis of surgery compared with intensive rehabilitation by using principles of cognitive behaviour therapy in the management of chronic pain of the low back. Although other economic evaluations of interventions for chronic low back pain have been published, ${ }^{24-26}$ only one compared operative and conservative treatment. ${ }^{24}$ Rehabilitation included in that study focused primarily on routine physiotherapy: comparison of cost effectiveness results between these two trials would not therefore be useful.

\section{Conclusion}

Although a policy of spinal fusion surgery as first line therapy for chronic low back pain seems not to be a cost effective use of healthcare resources at two year follow-up, our analyses have shown that this conclusion could alter if the number of rehabilitation patients subsequently receiving surgery continues to increase in the future. Only with further follow-up of patients can a robust and reliable estimate of the long term cost effectiveness of surgery compared with intensive rehabilitation in the management of chronic low back pain be obtained.

We thank the patients who permitted a difficult decision to be made for them, physiotherapists and surgeons both inside and outside the trial who helped develop the protocol and made the study possible, Anthony Morton for provision of unit costs, the Medical Research Council for supporting the study, and the NHS R\&D programme (especially Richard Lilford) for supporting and promoting the study.

Contributors: OR-A collected unit cost data, analysed resource use data, produced cost effectiveness estimates, and revised the paper. HEC supervised the collection of unit costs, analysed HRQoL data, wrote and revised the paper. AG designed and supervised the economic evaluation and revised the paper, and is guarantor of the economic analysis. JF was responsible for the overall trial design, the organisation of the trial, recruitment, surgical intervention, provision of unit costs, and revision of the paper. HF was responsible for overall trial design, the organisation of the trial, the design and implementation of the rehabilitation programme, and revising the paper. JW-M was responsible for overall trial design, the organisation of the study, recruitment, operating on trial participants, and editing 


\section{What is already known on this topic}

An economic evaluation of surgery for chronic low back pain that used unspecified physical therapy as the comparator indicated that surgery may be cost effective

A small trial reported that an intensive rehabilitation programme including cognitive behaviour therapy produced similar clinical benefits to spinal fusion surgery0

The cost effectiveness of surgery compared with such a programme has not been assessed

\section{What this study adds}

In the short term, compared with intensive rehabilitation, surgical stabilisation of the spine as first line treatment for chronic low back pain patients who have already failed standard non-operative care seems not be cost effective

If the number of rehabilitation patients observed having surgery continues to increase beyond two years, or the small treatment benefit at two years continues, this conclusion may change

the paper. Patricia Carver, Nuffield Orthopaedic Centre, was responsible for data collection, maintenance, and cleaning. Ly-Mee Yu, Centre for Statistics in Medicine, provided statistical advice and commented on the paper. Karen Barker, Nuffield Orthopaedic Centre NHS Trust, assisted with the collection of unit costs and provided valuable comments on the paper. Rory Collins, Clinical Trial Service Unit, Nuffield Department of Clinical Medicine, University of Oxford, was involved in the overall trial design and revising the manuscript. Douglas Altman, Centre for Statistics in Medicine, was responsible for statistical analysis and sat on the data monitoring committee. Nikolaos Maniadakis, Patras General University Hospital, assisted with the design of the economic evaluation. Katharine Johnston, Economics and Statistics Division, Scottish Executive, monitored progression of the study and produced power calculations. Lesley Morgan, Nuffield Department of Anaesthetics, John Radcliffe Hospital, was responsible for helping to set up the study, data collection, and database design. Kate Stevens, Victoria Erlanger, and Rebecca Bale (previous trial managers) collected and entered data. Peter Smith, X-I Interactive Database and Internet Solutions, developed and maintained the database.

Funding: This study was supported by the UK Medical Research Council. The NHS (326) or private patient insurance (23) funded the treatment of patients. The Health Economics Research Centre is partly funded by the National Coordinating Centre for Research Capacity Development. JF and JW-M receive funding from Synthes for a spinal fellow.

Competing interests: None declared.

Ethical approval: Granted by 15 local research ethics committees and one multicentre research ethics committee.

1 Maniadakis N, Gray A. The economic burden of back pain in the UK. Pain 2000;84:95103.

2 BUPA. Health information, ABC of health, back pain. http://hcd2.bupa.co.uk/fact_sheets/ mosby_factsheets/backpain.html (accessed 8 Apr 2005).

3 Fritzell P, Hägg P, Wessburg P, Nordwall A. 2001 Volvo award winner in clinical studies: lumbar fusion versus nonsurgical treatment for chronic low back pain. A multicenter randomized controlled trial from the Swedish lumbar spine group. Spine 2001:26:2521-34

4 Moller H, Hedlund R. Surgery versus conservative management in adult isthmic spondylolisthesis-a prospective randomized study: part 1. Spine 2000;25:1711-5.

5 Brox JI, Sorensen R, Friis A, Nygaard O, Indahl A, Keller A, et al. Randomized clinica trial of lumbar instrumented fusion and cognitive intervention and exercises in patients with chronic low back pain and disc degeneration. Spine 2003;28:1913-21.

6 Fairbank J, Frost H, Wilson-MacDonald J, Yu L, Barker K, Collins R, for the Spine Stabilisation Trial Group. The MRC spine stabilisation trial: a randomised controlled tria to compare surgical stabilisation of the lumbar spine versus an intensive rehabilitation programme for patients with chronic low back pain. BMJ 2005;330: (in press, May 28 progr
issue).

7 Fairbank JC, Couper J, Davies JB, O'Brien JP. The Oswestry low back pain disability questionnaire. Physiotherapy 1980;66:271-3.

8 Fairbank JC, Pynsent PB. The Oswestry disability index. Spine 2000;25:2940-52

9 EuroQol Group. EuroQol - a new facility for the measurement of health-related quality of life. Health Policy 1990;16:199-208.

10 Netten A, Curtis L. Unit costs of health and social care. Canterbury: Personal Social Services Research Unit, University of Kent, 2003.

11 MASS Group. Multicentre aneurysm screening study (MASS): cost-effectiveness analysis of screening for abdominal aortic aneurysms based on four year results from a randomised controlled trial. BMJ 2002;325:1135-41.

12 Dion P. The cost of anaesthetic vapours. Can J Anaesthesia 1992;39:633.

12 Dion P. The cost of anaesthetic vapours. Can J Anaesthesia 1992;39:633. base and comparative tool. Croydon: Institute of Public Finance, 2000.

14 Mallender Hancock Associates (MHA). National average specialty treatment and hotel costs. London: Department of Health, 1998.

15 Information Services Division NHS Scotland. The cost book 2003. www.isdscotland.org/ isd/info3.jsp?p_service $=$ Content.show\&pContentID $=360 \&$ \&_applic $=$ CCC\& (accessed 1 Jul 2004).

16 Department of Health. NHS reference costs 2003. Wetherby: DoH, 2004.

17 Bulman J. Patterns of pay: results of the 2003 new earnings survey. In: Labour Market Trends. Newport, Wales: Office for National Statistics, 2003:601-12.

18 Dolan P, Gudex C, Kind P, Williams A. The time trade-off method: results from a general population study. Health Econ 1996;5:141-54.

19 Great Britain H.M. Treasury. Green book, appraisal and evaluation in central government. London: Stationery Office, 2003 .

20 Van Buuren S, Boshuizen H, Knook D. Multiple imputation of missing blood pressure covariates in survival analysis. Stat Med 2000;18:681-94.

21 Briggs AH, Wonderling DE, Mooney CZ. Pulling cost-effectiveness analysis up by its bootstraps: a non-parametric approach to confidence interval estimation. Health Econ 1997;6:327-40.

22 Van Hout BA, Al MJ, Gordon GS, Rutten FF. Costs, effects and the C/E ratios alongside a clinical trial. Health Econ 1994;3:309-19.

23 Rawlins MD, Culyer AJ. National Institute for Clinical Excellence and its value judgments. BMJ 2004;329:224-7.

24 Fritzell P, Hagg O, Jonsson D, Nordwall A. Cost-effectiveness of lumbar fusion and nonsurgical treatment for chronic low back pain in the Swedish lumbar spine study: A multicenter, randomized, controlled trial from the Swedish Lumbar Spine Study multicenter, randomized, cont
Group. Spine 2004;29:421-34.

25 Skouen JS, Gradsal AL, Haldorsen EM, Ursin H. Relative cost-effectiveness of extensive and light multidisciplinary treatment programs versus treatment as usual for patients with chronic low back pain on long term sick leave: randomized controlled study. Spine 2002;27:901-9.

26 Kuntz KM, Snider RK, Weinstein JN, Pope MH, Katz JN. Cost-effectiveness of fusion with and without instrumentation for patients with degenerative spondylolisthesis and spinal stenosis. Spine 2000;25:1132-9.

(Accepted 29 March 2005)

doi $10.1136 /$ bmj.38441.429618.8F

Health Economics Research Centre, Department of Public Health, University of Oxford, Oxford OX3 7LF

Oliver Rivero-Arias research officer

Helen Campbell research officer

Alastair Gray professor of health economics

Nuffield Orthopaedic Centre, Oxford OX3 7LD

Jeremy Fairbank consultant orthopaedic surgeon

James Wilson-MacDonald consultant orthopaedic surgeom

Division of Health in the Community, University of Warwick, Warwick CV4 7AL

Helen Frost research fellow

Correspondence to: H Campbell helen.campbell@dphpc.ox.ac.uk 